\title{
CNI-1493, an inhibitor of proinflammatory cytokines, retards cartilage destruction in rats with collagen induced arthritis
}

\author{
E Larsson, H E Harris, K Palmblad, B Månsson, T Saxne, L Klareskog
}

Ann Rheum Dis 2005;64:494-496. doi: 10.1136/ard.2004.021550

Objective: To investigate if administration of $\mathrm{CNI}-1493$, an inhibitor of the synthesis of proinflammatory cytokines and $\mathrm{NO}$, protects against development of joint destruction in collagen induced arthritis (CIA) in rats.

Methods: In a placebo controlled experiment, $\mathrm{CNI}-1493$ was given once daily intraperitoneally after onset of clinical arthritis in DA rats. Disease progression was studied by clinical scoring of arthritis, serial measurement of serum levels of COMP, and histological examination of joints.

Results: Clinical signs of arthritis were significantly reduced in the $\mathrm{CNI}-1493$ treated group of rats in comparison with the placebo treated group. Histological examinations of paws demonstrated a significant reduction of cartilage destruction in the $\mathrm{CNI}-1493$ treated group, but marked destruction of cartilage in the placebo group. Serum levels of COMP increased in the placebo group, whereas in the CNI-1493 treated group levels were low and decreased significantly during the observation time.

Conclusions: Treatment with CNI-1493 provides efficient protection against synovial inflammation and cartilage destruction when used therapeutically in CIA. The protective effect against cartilage destruction can be monitored by measuring serum COMP. These observations make CNI1493 an attractive candidate for therapeutic studies in human arthritis, and COMP an attractive serum marker for monitoring joint protective effects.

D estruction of the joints is one of the most serious consequences of rheumatoid arthritis (RA). Despite recent progress in treatment, new drugs which can efficiently inhibit joint inflammation and destruction are needed. As inflammation and destruction are not always parallel processes, there is also a need for diagnostic tools, which can be used to evaluate the effects of new drugs, particularly on joint destruction.

CNI-1493 is a tetravalent guanylhydrazone, which was originally developed to inhibit cytokine inducible $\mathrm{NO}$ production, ${ }^{1}$ but it also inhibits the production of proinflammatory cytokines such as tumour necrosis factor (TNF), interleukin (IL) $1 \alpha$ and $\beta$, IL6, and macrophage inhibitory protein-1. ${ }^{2}$ Administration of CNI-1493 to rats with collagen induced arthritis (CIA) has previously been shown to retard development of clinical signs of arthritis, but the effects of CNI-1493 on cartilage or bone destruction were not investigated. A recent report, demonstrating effects of CNI-1493 on inflammatory bowel disease, ${ }^{4}$ has renewed interest in this drug also for chronic arthritis.

We investigated the effects of CNI-1493 on the development of joint destruction in CIA. Changes in serum cartilage oligomeric matrix protein (COMP) levels as a marker of cartilage turnover ${ }^{5}$ and joint histology were used to measure how CNI-1493 influences the development of cartilage destruction.

\section{MATERIALS AND METHODS}

Animals

Female DA rats aged 3.5-4 months at the start of the experiments were used. The ethical board for animal experiment in Stockholm-North approved this study.

\section{Induction and clinical monitoring of CIA}

Collagen II was prepared from rat chondrosarcoma as previously described. ${ }^{67}$ The collagen was dissolved in $0.1 \mathrm{M}$ acetic acid and emulsified 1:1 with Freund's incomplete adjuvant (Difco, Detroit, MI, USA). Collagen II (150 $\mu \mathrm{g})$ in $200 \mu \mathrm{l}$ emulsion was injected intradermally once at the base of the tail at day 0 .

Each paw was scored as follows: $0=$ no arthritis; $1=$ swelling in one type of joint; 2 = swelling in two types of joint; $3=$ swelling in three types of joint; and $4=$ swelling of the entire paw. A total score for an animal was calculated by summing the scores for the four paws, resulting in a maximal score of $16 .{ }^{8}$ The scoring was made by two blinded observers. The rats were scored daily and the first sign of arthritis was noticed at day 13 after immunisation.

Blood samples were taken by retro-orbital puncture before immunisation and at days 14, 21, 23, and26 after immunisation. The rats were killed at day 26 after immunisation.

\section{Treatment}

CNI-1493 was given in a dosage described to be efficient in affecting joint inflammation, ${ }^{3}$ - that is, $5 \mathrm{mg} / \mathrm{kg} /$ day intraperitoneally, to 15 animals. Fifteen control animals received $\mathrm{NaCl}$. Treatments were initiated when the joint score was $>1$. CNI-1493 was obtained from K J Tracey, Picower Institute for Medical Research, Manhasset, NY, USA.

\section{Immunoassay of COMP}

Serum concentrations of COMP were determined by enzyme linked immunosorbent assay (ELISA), using rat COMP for coating of microtitre plates and for the standard curve included in each plate together with a polyclonal antiserum raised against rat COMP.?

\section{Histological examinations}

Paws from rats were fixed in $4 \%$ phosphate buffered formaldehyde. Subsequently the specimens were decalcified with $14 \%$ ethylenediaminetetra-acetic acid (EDTA) in $0.36 \mathrm{M}$

Abbreviations: $\mathrm{CIA}$, collagen induced arthritis; COMP, cartilage oligomeric matrix protein; IL, interleukin; RA, rheumatoid arthritis, TNF, tumour necrosis factor 


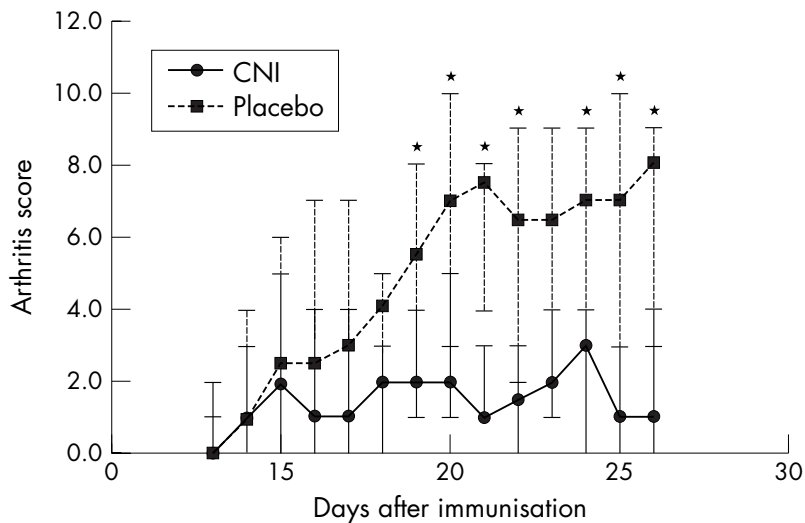

Figure 1 Disease scores. The maximum score in the arthritic model is 16 points. From day 19 the placebo group has a significantly higher score than the CNI-1493 treated group (except at day 23). CNI-1493 at days 14-22, $n=13$; at days 22-23, $n=12$; at days $24-26, n=7$. Placebo at days 14-23, $n=14$; at days $24-26, n=9$. All values are medians (interquartile range). ${ }^{*} \mathrm{p}<0.05 \mathrm{CNI}$ group $v$ placebo group.

$\mathrm{NaOH}$, dehydrated, and embedded in paraffin blocks. Sections ( $8 \mu \mathrm{m}$ thick) were cut, mounted on slides, and stained with haematoxylin and eosin. ${ }^{8}$ The slides were examined with a Reichart-Jung Polyvar 2 light microscope.

The histological grading is a modified version of a system adopted from Joosten et al. ${ }^{10}$ For each animal both hind paws were examined. Cell infiltration in synovial fluid was graded on a scale from 0 to 3 as follows: $0=$ no inflammatory cells in the joint cavity; $1=$ presence of a few inflammatory cells in the joint cavity; 2 = joint cavity partly filled with inflammatory cells; and $3=$ joint cavity totally filled with inflammatory cells. Synovitis was graded from 0 to 3 as follows: $0=$ healthy, uninflamed appearance of synovia; $1=$ mild thickening of synovia; 2 = substantial thickening of synovia; and $3=$ severe thickening of synovia. Destruction of cartilage was graded from 0 to 3 as follows: $0=$ normal histology; $1=$ minor destruction on the cartilage surface; $2=$ clear loss of cartilage; and $3=$ cartilage almost absent in a whole joint. Bone involvement was graded from 0 to 3 as follows: $0=$ normal histology; $1=$ minor signs of destruction; $2=$ up to $30 \%$ destruction; and $3=$ more than $30 \%$ destruction.

Two observers performed all histological evaluations in a blinded manner. The presented data are the mean values of the observations.

\section{Statistical analysis}

Wilcoxon's matched pairs test (two tailed) was used for comparing concentrations of COMP and clinical arthritis scores at different times. The Mann-Whitney U-test was used for comparing differences between groups. A p value $<0.05$ was considered significant. Only animals developing disease were included in the calculations.

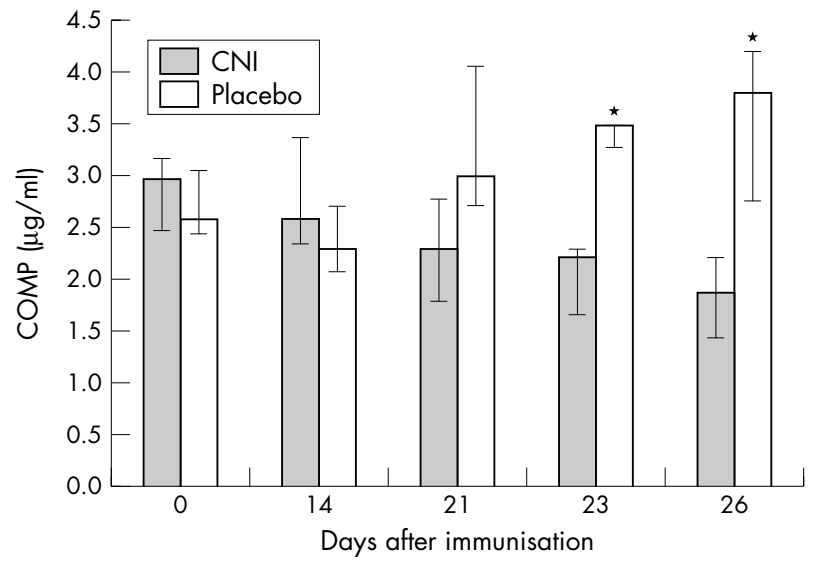

Figure 2 Serum levels of COMP. $\mathrm{CNI}-1493$ at day 14, $\mathrm{n}=13$; at day $23, \mathrm{n}=5$; and at day $26, \mathrm{n}=7$. Placebo at day $14, \mathrm{n}=14$; at day 23 , $n=5$; and at day $26, n=9$. All values are medians (interquartile range). ${ }^{*} \mathrm{p}<0.05 \mathrm{CNI}$ group $\vee$ placebo group.

\section{RESULTS}

\section{Development of disease}

Figure 1 presents the arthritis scores. Ninety per cent (27/30) of the animals exhibited clinical signs of arthritis. The onset of disease occurred between days 13 and 21 after immunisation.

\section{Histology}

Table 1 shows the histology results obtained. At day 23 after immunisation five animals in each group were killed for histological examination and the remaining animals were killed at day 26 after immunisation.

\section{Serum concentrations of COMP}

The COMP levels increased after arthritis onset in the placebo treated group but remained low in the CNI-1493 treated group. The levels of COMP were significantly higher in the placebo group at days 23 and 26 after immunisation compared with the CNI-1493 treated group (fig 2), and the levels of COMP decreased significantly over time in the CNI1493 group $(\mathrm{p}<0.05$ at day 26 after immunisation)

\section{Toxicity}

Placebo treated rats lost more weight than CNI-1493 treated rats (data not shown), and no severe side effects were noticed in the CNI-1493 treated group

\section{DISCUSSION}

We have shown that treatment with CNI-1493 prevents development of cartilage destruction in rats with CIA. The destruction of cartilage is followed by an increase in serum levels of COMP, and the preventive effects of CNI-1493 on cartilage destruction are accompanied by decreasing serum

Table 1 Quantification of joint inflammation and damage by histology

\begin{tabular}{|c|c|c|c|c|}
\hline & $\begin{array}{l}\text { Synovial tissue } \\
\text { inflammationt }\end{array}$ & $\begin{array}{l}\text { Synovial fluidt } \\
\text { (exudates) }\end{array}$ & $\begin{array}{l}\text { Cartilage } \\
\text { involvement }\end{array}$ & $\begin{array}{l}\text { Bone } \\
\text { involvementł }\end{array}$ \\
\hline $\begin{array}{l}\text { Placebo day } 23 \\
\text { Placebo day } 26 \\
\text { CNI-1493 day } 23 \\
\text { CNI-1493 day } 26\end{array}$ & $\begin{array}{l}3(1-3) \\
6(1-6) \\
0(0-0) \\
0(0-3)^{*}\end{array}$ & $\begin{array}{l}2(1-2) \\
3(0-4) \\
0(0-1) \\
0(0-2)\end{array}$ & $\begin{array}{l}1(0-2) \\
6(0-6) \\
0(0-0) \\
0(0-2)^{*}\end{array}$ & $\begin{array}{l}2(0-2) \\
3(0-6) \\
0(0-0) \\
0(0-2)\end{array}$ \\
\hline \multicolumn{5}{|c|}{$\begin{array}{l}\text { Values are median (interquartile range). } \\
\text { * } \mathrm{p}<0.02 \text { (CNI- } 1493 \text { treated } v \text { placebo treated group); tby histological grading: } 0=\text { normal, } 6=\text { maximal } \\
\text { inflammation; tby histological grading: } 0=\text { normal, } 6=\text { maximal destruction. }\end{array}$} \\
\hline
\end{tabular}


COMP levels, indicating that serum COMP provides an efficient and rapid way of monitoring cartilage protective effects of CNI-1493.

The correlation between cartilage destruction, as identified by histology, and increased serum levels of COMP has been demonstrated previously ${ }^{5}$; the current results confirm and extend these previous observations. Furthermore, this work and a previous study, ${ }^{11}$ indicate that measurement of serum COMP might be of value for determining the effects of drugs on cartilage destruction also in short term studies in RA.

The exact actions of the drug are not fully understood. It may modify local inflammation by affecting production of several proinflammatory molecules, such as TNF, IL1 $\beta$, IL6, and other inflammatory mediators of macrophage origin, by interfering with the p38 MAPK pathway. ${ }^{212}$ CNI-1493 may, however, also exert anti-inflammatory effects by stimulating parasympathetic actions of the vagus nerve and thereby prevent inflammation by a previously unrecognised pathway. ${ }^{13}$ It cannot be concluded from previous studies whether CNI-1493 can prevent joint destruction. Our study demonstrates that CNI-1493 does indeed both prevent joint inflammation and joint destruction when instituted after onset of disease, which is encouraging for potential future trials in human RA. Such studies may be warranted as the drug has recently been demonstrated to have positive effects in Crohn's disease. ${ }^{4}$ The existing similarities in cytokine expression and in treatment results between RA and Crohn's disease $^{14}$ suggest that CNI-1493 might be effective in RA and therefore warrants a clinical trial in RA.

\section{ACKNOWLEDGEMENTS}

We thank Mette Lindell for skilful technical assistance, and Dr RA Harris for critically reading the manuscript.

The Swedish Medical Research Council, the Österlund, Kock and Crafoord Foundations, the King Gustaf V 80-year Fund, Reumatikerförbundet, Börje Dahlin Foundation, and Nanna Svartz Foundation helped to fund the study.

\footnotetext{
Authors' affiliations

E Larsson, H E Harris, L Klareskog, Rheumatology Unit, Department of Medicine, Karolinska Hospital, Stockholm, Sweden

K Palmblad, Rheumatology Unit, Astrid Lindgren's Children's Hospital, Karolinska Hospital, Stockholm, Sweden

B Månsson, T Saxne, Department of Rheumatology and Department of Cell and Molecular Biology, Lund University, Sweden
}

Correspondence to: Dr E Larsson, Rheumatology Unit, Department of Medicine, Karolinska Hospital, S-171 76 Stockholm, Sweden; esbjorn.larsson@karolinska.se

Accepted 20 June 2004

\section{REFERENCES}

1 Bianchi $M$, Ulrich $P$, Bloom O, Meistrell M. 3rd, Zimmerman GA, Schmidtmayerova $\mathrm{H}$, et al. An inhibitor of macrophage arginine transport and nitric oxide production (CNI-1493) prevents acute inflammation and endotoxin lethality. Mol Med 1995; 1:254-66.

2 Bïork L, Tracey KJ, Ulrich P, Bianchi M, Cohen PS, Åkerlund K, et al. Targeted suppression of cytokine production in monocytes but not in T lymphocytes by a tetravalent guanylhydrazone (CNI-1493). J Infect Dis 1997;176:1303-12.

3 Åkerlund K, Erlandsson Harris H, Tracey KJ, Wang H, Fehniger T, et al. Antiinflammatory effects of a new tumour necrosis factor-alpha (TNF-alpha) inhibitor (CNI-1493) in collagen-induced arthritis (CIA) in rats. Clin Exp Immunol 1999;115:32-41.

4 Hommes D, van den Blink B, Plasse T, Bartelsman J, Xu C, Macpherson B, et al. Inhibition of stress-activated MAP kinases induces clinical improvement in moderate to severe Crohn's disease. Gastroenterology 2002;122:7-14.

5 Larsson E, Müssener A, Heinegård D, Klareskog L, Saxne T. Increased serum levels of cartilage oligomeric matrix protein and bone sialoprotein in rats with collagen arthritis. Br J Rheumatol 1997;36:1258-61.

6 Smith BD, Martin GR, Miller EJ, Dorfman A, Swarm R. Nature of the collagen synthesized by a transplanted chondrosarcoma. Arch Biochem Biophys 1975; 166:181-6.

7 Larsson P, Kleinau S, Holmdahl R, Klareskog L. Homologous type II collageninduced arthritis in rats. Characterization of the disease and demonstration of clinically distinct forms of arthritis in two strains of rats after immunization with the same collagen preparation. Arthritis Rheum 1990;33:693-701.

8 Kleinau S, Erlandsson H, Holmdahl R, Klareskog L. Adjuvant oils induce arthritis in the DA rat. I. Characterization of the disease and evidence for an immunological involvement. J Autoimmun 1991;4:871-80.

9 Vingsbo-Lundberg C, Saxne T, Olsson H, Holmdahl R. Increased serum levels of cartilage oligomeric matrix protein in chronic erosive arthritis in rats. Arthritis Rheum 1998;41:544-50.

10 Joosten LA, Helsen MM, Saxne T, van De Loo FA, Heinegård D, van Den Berg WB. IL-1 alpha beta blockade prevents cartilage and bone destruction in murine type II collagen-induced arthritis, whereas TNF-alpha blockade only ameliorates joint inflammation. J Immunol 1999; 163:5049-55.

11 Larsson E, Erlandsson Harris H, Larsson A, Mansson B, Saxne T, Klareskog L. Corticosteroid treatment of experimental arthritis retards cartilage destruction as determined by histology and serum COMP. Rheumatology (Oxford) 2004;43:428-34.

12 Cohen PS, Schmidtmayerova H, Dennis J, Dubrovsky L, Sherry B, Wang H, et al. The critical role of p38 MAP kinase in T cell HIV-1 replication. Mol Med 1997;3:339-46.

13 Bernik TR, Friedman SG, Ochani M, DiRaimo R, Ulloa L, Yang H, et al. Pharmacological stimulation of the cholinergic antiinflammatory pathway. J Exp Med 2002;195:781-8.

14 Feldmann M, Taylor P, Paleolog E, Brennan FM, Maini RN. Anti-TNF alpha therapy is useful in rheumatoid arthritis and Crohn's disease: analysis of the mechanism of action predicts utility in other diseases. Transplant Proc 1998;30:4126-7. 